\title{
Modelling of Wax Actuators in Underfloor Heating Manifolds
}

\author{
Tuule Mall Kull ${ }^{1 *}$, Martin Thalfeldt ${ }^{2,1}$, and Jarek Kurnitski ${ }^{2,1,3}$ \\ ${ }^{1}$ Nearly Zero Energy Buildings Research Group, Tallinn University of Technology, Ehitajate tee 5, 19086 Tallinn, Estonia \\ ${ }^{2}$ Smart City Center of Excellence, Tallinn University of Technology, Ehitajate Tee 5, 19086 Tallinn, Estonia \\ ${ }^{3}$ Department of Civil Engineering, Rakentajanaukio 4 A, Aalto University, FI-02150 Espoo, Finland
}

\begin{abstract}
Finding sources for power grid balancing has become increasingly important with more renewables used for production. In buildings, heat pumps could be utilized among other electrical appliances. The heat pumps would work at full power to balance the overproduction in the grid. However, short-term grid flexibility announces the consumption need up to 5 minutes in advance, which can prove a problem to control. When there is no current energy need in the building, all valves are closed. That means that when a heat pump with overridden control starts working at the maximum frequency, its full power heats up the local circuit very fast, especially when there is no storage tank. Whether the heat pump overheats and cannot be used for balancing the grid or the whole system opens for heating depends on the regulating valves and their opening speed. For underfloor heating systems, the valve opening speed is slower than for other systems as wax actuators are used. This paper focuses on how to model these wax actuators and determine the opening time to provide input for further studies on flexibility. A physical and a linear segment model are parameterized and the results show that the wax actuator fully opens the valve in six minutes.
\end{abstract}

\section{Introduction}

Power grid that is rich in renewable energy, faces an increasingly difficult challenge of ensuring the grid power frequency at the needed $50 \mathrm{~Hz}$ level. The frequency stays constant when production and demand are in balance. When production changes rapidly, it can be faster and cost-efficient to change the demand rather than switch on or off other production sources. In demand side management, large consumers such as factory lines are a logical option. However, as the building sector consumes $30 \%$ of electrical energy globally [1], buildings cannot be omitted as a possible flexibility source. It could be possible to switch household electrical appliances, but the increasing use of heat pumps allows using thermal energy storage in buildings to balance the power grid as well [2]. Energy flexible buildings have been discussed in detail in IEA EBC Annex 67 project [3]. Several control methods have been developed to utilize either the storage tank or structural thermal storage in buildings for flexibility [4].

However, the grid changes are quick and in the solution where many heat pumps are aggregated to an overhead system, the individual heat pumps get the signal to create demand only about $5 \mathrm{~min}$ in advance [5]. The control would overrun the default approach and the frequency would be set manually [6]. While small inverter based heat pump systems do not need large storage tanks, the system volume is very small when valves towards the rooms are closed. This could result in overheating or -cooling when the heat pump is started at full power. Therefore, to accurately predict what happens in the heat pump circuit, the slowest components have to be modelled precisely. Next to the heat pump itself, the only variable that controls the circuit are the actuators on the regulating valves. For underfloor heating, these are wax actuators in the manifold's return side.

Wax actuators are electrically controlled PCM (phase change material) actuators where paraffin wax is heated by a PTC (positive temperature coefficient) heater. These actuators are also called wax pellet actuators [7], thermal actuators, wax motors [8]. The actuator is screwed to the valve, which is therefore normally closed. When the voltage is applied, the wax starts to melt and expands. This expansion moves the piston, and with a system of springs, the actuator inner height reduces, which opens the valve. This type of actuators have been widely used for fan coils and in manifolds for TABS systems as well as hydronic underfloor heating for a long time as they are silent and strong. The core of the wax actuator is shown in Figure 1 (a) and the cross-section of the wax actuator in Figure 1 (b).

Actuators are mostly omitted in building energy performance simulations as their time constant is in orders of magnitude smaller than for the whole system. Sometimes these are modelled in a simplified mathematical way as a delay [9]. In other fields, wax actuators have mostly been modelled for microfluid systems in the scientific literature, however with nonmoving parts and therefore with an upscaling challenge [10]. In the actuator industry, it is common to model the actuator movement as hysteresis [8]. The

* Corresponding author: tuule.kull@taltech.ee 
PCMs have been modelled in building structures as a thermal hysteresis as well [11]. The characteristics of the paraffin wax used in the actuators have been analysed in several articles [12]-[14]. However, wax actuator models that are more detailed than delay models are not discussed in the scientific literature for buildings and HVAC until now.

For grid flexibility, a timescale of 5 minutes has to be analysed and wax actuators are in that range. Therefore, the wax actuators should be modelled more precisely. In the current paper, we compare the physical and mathematical models for wax actuator. The main novelty of this paper is in the detailed modelling of the wax motor together with the valve and calibrating these in an actual system. This paper applies the wax motor model developed by Lars Eriksson in EQUA's IDA ICE software library [15] for the first time in the scientific literature. Moreover, in the HVAC science, possible parameters for wax motor have not been published before.

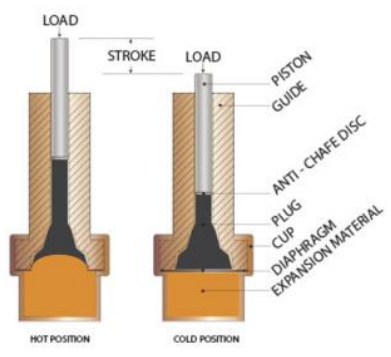

(a)

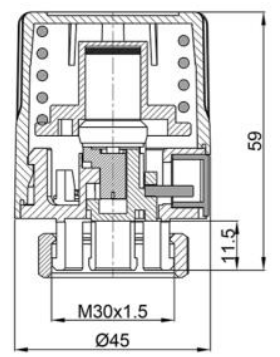

(b)
Figure 1. (a) Wax pellet actuator core [8] and (b) a crosssection how it is reversely implemented in a wax motor [16].

\section{Methods}

\subsection{Experiment setup}

The experiments are carried out in two phases to determine the effect of actuator only and actuator together with a valve. Initially, the wax actuator was unmounted from the valve and the change in its height with periodic applying of voltage was measured. In the second phase, the wax actuator was mounted in an underfloor heating manifold and the height could not be directly measured but the mass flow through the system could be.

\subsubsection{Phase 1 : Linear movement of the actuator}

A commercial $24 \mathrm{~V}$ wax actuator produced and installed in 2013 was placed between a digital calliper with data logging capability. A metal piece was added between the calliper and the wax motor bottom to enable measuring the change in height. The calliper was fixed with a rubber band so that when the actuator's height reduces, the calliper would keep contact with the actuator and measure the change in height. Clearly, the measuring method and devices could be improved, especially as the force applied on the actuator by the calliper was not measured. However, this force is small and presumably has no major effect. Therefore, this approach can be used for this preliminary study.

The wax actuator was controlled by a $24 \mathrm{~V} \mathrm{DC}$ onoff signal with 15 minutes $\mathrm{ON}$ and 15 minutes OFF, periodically for 10 hours. The voltage control was implemented and logged in Siemens LOGO! 24CE controller [17]. The first hour was not used for parameter fitting.

\subsubsection{Phase 2 : Mass flow through the valve}

In the second phase, the wax actuator was mounted on a regulating return valve in an underfloor heating manifold. It is a typical hydronic underfloor heating manifold with 8 circuits in a small residential house. Its water is heated by a heat pump to a storage tank. From the tank, a pump in the mixing valve circulates the water through the manifold and circuits. In the mixing station, the thee-way valve is set to fully open with no recirculation. Pump speed was set to be constant. The setup consists of commercial products, so it is not exactly known what is inside each component. All parameter estimates depend on the documentation of the products.

To enable measuring the mass flow through one valve only, all but one valve in the manifold were closed by a commercial controller by setting the setpoints for the corresponding rooms (circuits) very low. The observed wax actuator on the last valve was again controlled by the Siemens LOGO controller. As the linear opening could not be directly measured, the mass flow through the manifold was measured by a heat meter. As additional measures, the surface temperature of the wax actuator was measured as well as the opening indicator on the cover was filmed for some cycles.

For surface temperature measurement, a PT100 sensor with data logging was glued to the plastic cover of the actuator on the side with thermal paste improving the thermal contact. The sensor was not insulated from the ambient air as otherwise the motor would cool down and close much slower than without it.

This time the wax actuator was observed for 3.5 days, the first two days the actuator was controlled with a signal of 15 minutes $\mathrm{ON}$ and 45 minutes OFF, and the last two days the signal was 15 minutes $\mathrm{ON}$ and 15 minutes OFF.

\subsection{Modelling}

The actuator was described by two models:

- Characteristic curve model

- Physical model

Both models calculate the linear position of the piston based on the voltage applied to the wax actuator. Pure hysteresis model was not included in this paper but should be analysed in future works.

The valve model was used to translate the linear piston movement of the actuator into mass flow through the valve. 


\subsubsection{Actuator: characteristic curve}

The characteristic curve model is a linear segment model determined by four parameters: dead time, rise time, hold time, and fall time. The principle graph is shown in Figure 2. The model has four parameters. The dead time occurs when the voltage is turned on and therefore the PTC heater has started to heat the wax but the wax has not reached the melting point yet. During the rise time, the wax melts and expands, which moves the piston. When all wax has melted, its temperature increases but it does not expand and move the piston further. When the voltage turns off, the wax cools down. Before it reaches the melting point, it does not start to contract. This time is called hold time. When the solidification and therefore contraction starts, the hold time ends and fall time starts. Fall time ends when the actuator reaches its cold height. All four parameters were determined for each heating cycle in Phase 1. Average parameter value over all cycles was used for comparison simulations.

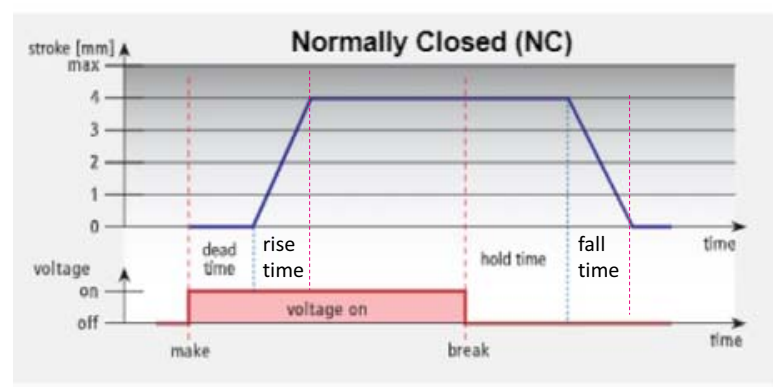

Figure 2. Characteristic curve model of linear segments for the actuator, adapted from [18]

\subsubsection{Actuator: physical model overview}

The physical model is based on first principles and was developed by Lars Eriksson at EQUA AB in 2017 for a private company. It has been published together with IDA ICE software. However, to keep the company's secret, the original parameter values were deleted. The adjustable parameters, their default and potential value ranges are discussed in the next section. The model uses enthalpy levels to keep track of the wax state in the motor. The model implementation is shown in Figure 3.

The main limitations of the model include the lack of modelling all springs in the system and that the heat transfer to the ambient is greatly simplified. The heat exchange with ambient is modelled with only resistance without capacitance and the ambient temperature is only an input not enabling the generation of heat balance. Therefore, the heat transfer to ambient is just dependent on the input temperature from the ambient and the resistance. To use the air temperature in the room where the manifold is situated, the resistance would have to be large. Moreover, the delays due to the capacity of the plastic cover cannot be described. Not modelling springs increases the same effect. For improvement, the surface temperature can be used as input. As the surface temperature is not measured in typical applications, it was not included in Phase 1. However, it was added in Phase 2 to enable calibration.

The lack of surface temperature in Phase 1 was solved with the measured room air temperature plus a second-order transfer function from the heating signal. Its parameters gain $\mathrm{k}$, damping $\mathrm{D}$, and angular frequency $\mathrm{w}$ were fit to Phase 2 experimental surface temperature via IDA ICE parametric runs connection to GenOpt [19]. The possible value ranges were estimated from time constants as we expect the first time constant to be close to an hour and the second time constant to be close to a minute. As transfer function denominator:

$$
\left(\tau_{1} s+1\right)\left(\tau_{2} s+1\right)=(s / w)^{2}+2 D(s / w)+1
$$

Then:

$$
\begin{gathered}
w=1 / \sqrt{\tau_{1} \tau_{2}} \\
D=w\left(\tau_{1}+\tau_{2}\right) / 2
\end{gathered}
$$

These give the initial estimates of $\mathrm{w}$ and $\mathrm{D}$ to be around 0.002 and 4 . Gain represents the temperature change between the room and wax temperature.

\subsubsection{Actuator: physical model parameter estimation}

The parameters and their possible values for the physical model are shown in Table 1. $\mathrm{N}$ describes how many different ambient temperatures and resistances are modelled. This was kept at one. $\mathrm{U}$ defines the input voltage at signal 1, which for the used actuators is $24 \mathrm{~V}$. Maximum displacements of the valve and actuator were set to the same values to initially exclude the valve effect. The displacement of $3.25 \mathrm{~mm}$ was determined from the Phase 1 measurements, although when defined equal, this effect is eliminated as the output of the model is the position in decimal percentage. This will be later multiplied with the known maximum displacement for error evaluation. The last parameter set to a constant is $\mathrm{T}_{\mathrm{HO}}$. It is described as ,Temperature at which $H=1 E 5$ $\mathrm{J} / \mathrm{kg}$ (default initial value of $H$ ). If initial value of $H$ isn't changed, $T_{-} H O$ becomes initial value of $T$. " [15] As the initial value of $\mathrm{H}$ was not changed and the absolute values of enthalpy are not of interest only the relative differences, this can be fixed to some chosen value. Default value was used.

As wax motors are declared to work in ambient temperatures up to 60 degrees [18], [20], the melting temperature T_MELT has to be higher than this. Specific heat capacity in solid state CP_SOL can be according to different sources, for example, 2384 or $2604 \mathrm{~J} /(\mathrm{kg} \mathrm{K})$ and for liquid state (CP_FLU) $2981 \mathrm{~J} /(\mathrm{kg}$ K) [21], or $2100 \mathrm{~J} /(\mathrm{kg} \mathrm{K})$ for both [22]. These values were included in the chosen range for both parameters. The melting heat should vary from 200 to $220 \mathrm{~J} / \mathrm{g}$ [21]. Estimating that there should be around $1 \mathrm{~cm}^{3}$ of wax with a density of $0.8 \mathrm{~g} / \mathrm{cm}^{3}$ [21], the mass range $\mathrm{M}$ can be guessed.

The parameters R_25 and T_CURIE describe the PTC heater. T_CURIE is the temperature where the resistance becomes infinite large, ranging from 60 to 
$140{ }^{\circ} \mathrm{C}$, for thermal actuators is typically at $90{ }^{\circ} \mathrm{C}$ [23]. $\mathrm{R} \_25$ is the resistance at $25^{\circ} \mathrm{C}$, a possible value from the literature is $50 \mathrm{~K} / \mathrm{W}$ [24]. Between the surface temperature and the wax, the materials and air result in a thermal resistance described by $\mathrm{R}$. Assuming only insulation, this would be $100 \mathrm{~K} / \mathrm{W}$ and only plastic 0.3 $\mathrm{K} / \mathrm{W}$.

Suitable values for all parameters were found with GenOpt (through IDA ICE Parametric Runs) minimizing the MAE (mean absolute error) between the measured and simulated linear piston movement.

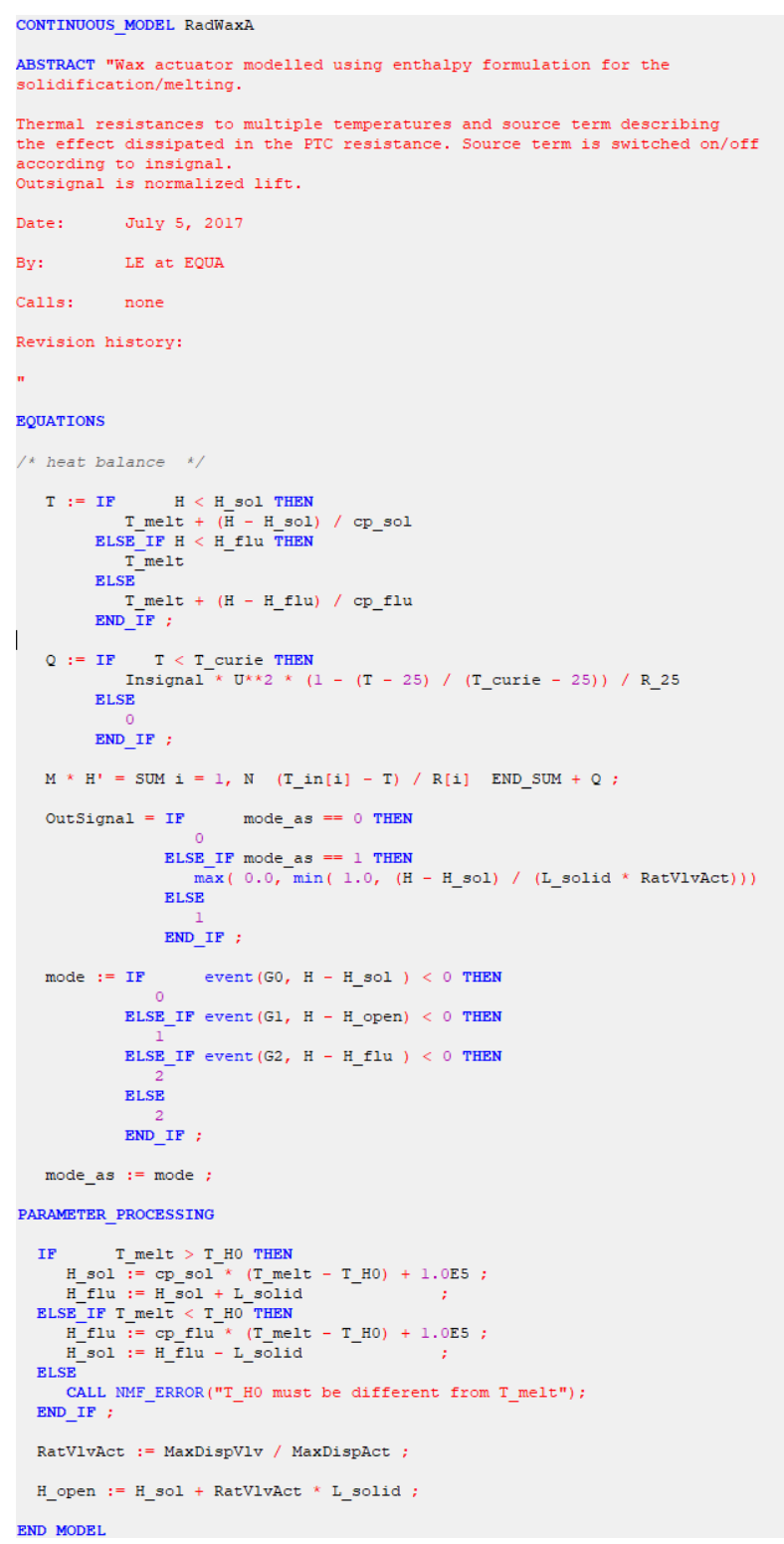

Figure 3. The implementation of wax actuator in IDA ICE, the definition of all links, variables, and parameters has been omitted here for conciseness

\subsubsection{Valve model}

Modelling the actuator and valve together would need to transform the linear piston movement from the actuator model into water flow. This is characterized by a valve characteristic that maps the piston position to the percentage of nominal flow. Manifold valves should mostly be quick opening valves, as indicates the shape of valve (5) in Figure 4 (a). Quick opening is not very clearly defined, so the shape of the characteristic curve has to be determined experimentally.

In addition, valve authority distorts the valve characteristic in an experimental setting. Both curves are shown in a hypothetical example in Figure 4 (b). Valve authority is defined as the ratio of valve pressure drop to total pressure drop. In the observed system, the circuit starting from the storage tank can be observed as a separate system and therefore, the components towards the heat pump are not taken into account for pressure drop analysis.

The whole system has been balanced for $800 \mathrm{l} / \mathrm{h}$ with a balancing valve Comap DN 251 " at $3 \mathrm{kPa}$ the position 28 has been chosen (but zero has shifted, so the actual position was 27) using the producer's nomograms [25]. When closing all other circuits, the balancing valve position was adapted to 9 , and the volume flow of a maximally open valve is at $G_{\max }=240 \mathrm{l} / \mathrm{h}$. The component wise pressure drops are estimated via various sources [26] and shown in Table 2. The estimation of all components started from the assumption that the pump pressure head stays constant, which is approximately valid as the pump curve at average speed and volume flow below 800 1/s varies less than $1 \mathrm{kPa}$ [27]. All other components add up to $d p_{\text {sys }}=$ $27.2 \mathrm{kPa}$ pressure drop. Therefore, the valve pressure drop is $2.9 \mathrm{kPa}$ and the $\mathrm{K}_{\mathrm{v}}$ of the regulating valve is estimated to be:

$$
K_{v}=\frac{0.01 \cdot \dot{V}}{\sqrt{d p_{\text {valve }}}} \approx 1.4
$$

and valve authority

$$
N=\frac{d p_{\text {valve }}}{d p_{\text {valve }}+d p_{\text {sys }}} \approx 0.1
$$

The valve authority is very low, which is a result of observing only one circuit in a system which is designed for several circuits.

The actual volume flow is the volume flow from the valve curve distorted by the authority, which can be calculated from [28]:

$$
G_{\%}=\sqrt{\frac{\frac{1}{N}}{\frac{1}{N}-1+\frac{1}{k^{2}}}}
$$

where $G_{\%}$ is the actual flow rate (in decimal percentage), $\mathrm{N}$ is the valve authority calculated for the given linear valve position, and $\mathrm{k}$ is the ratio of nondistorted and maximal flow rates. As the valve authority changes for the regulating valve during its opening and closing, the calculation was reversed. We assumed $G_{\%}$ from 0 to 1 , and at each step calculated N. As $d p_{\text {valve }}+d p_{\text {sys }}=$ $d p_{\text {pump }}$, valve authority can be calculated at any valve openness:

$$
N=\frac{d p_{\text {pump }}-d p_{\text {sys }}}{d p_{\text {pump }}}=1-\frac{d p_{\text {sys }}}{d p_{\text {pump }}}=1-\frac{\left(G / K_{\text {visys }}\right)^{2}}{d p_{\text {pump }}}
$$


Where $\mathrm{G}$ is the actual volume flow $G_{\%} G_{\max }$ and $K_{v \text {,sys }}$ is calculated from $d p_{\text {sys }}$, and $G_{\max }$. Now $\mathrm{k}$ can be derived from Eq. (6:

$$
k=\sqrt{\frac{1}{\frac{1}{N G_{\%}{ }^{2}}-\frac{1}{N}+1}}
$$

And therefore, we have derived the nondistorted volume flow from the distorted as $G_{v c}=k\left(G_{\%}\right) \cdot G_{\max }$. Assuming that the quick opening pattern is similar to a logarithmic curve, usually the volume flow would be calculated from the stroke percentage $h_{\%}$ as:

$$
G_{v c}=\frac{\ln \left(h_{\%}\right)}{\ln (100 \%)} G_{\max }
$$

Therefore, now we can calculate backwards:

$$
h_{\%}=e^{k \cdot \ln (100)}
$$

When the mapping was once calculated as reversed, it was numerically saved and could be later used for calculating the volume flow from the piston linear position.

Table 1. The parameters and their value ranges of the physical model, bold values were fixed, based on prior knowledge

\begin{tabular}{|c|c|c|c|}
\hline Name & Default & $\begin{array}{c}\text { Initial value } \\
\text { (limits) }\end{array}$ & Unit \\
\hline $\mathrm{N}$ & 1 & $\mathbf{1}$ & items \\
\hline $\mathrm{M}$ & 0.0005 & $\begin{array}{c}0.0008 \\
(0.0005 \text { to } 0.002)\end{array}$ & $\mathrm{kg}$ \\
\hline CP_SOL & 1200 & $\begin{array}{c}2100 \\
(2100 \text { to } 3000)\end{array}$ & $\begin{array}{c}\mathrm{J} / \\
(\mathrm{kg} \mathrm{K})\end{array}$ \\
\hline CP_FLU & 1200 & $\begin{array}{c}2100 \\
(2100 \text { to } 3000)\end{array}$ & $\begin{array}{c}\mathrm{J} / \\
(\mathrm{kg} \mathrm{K})\end{array}$ \\
\hline L_SOLID & 200000 & $\begin{array}{c}210000 \\
(200000-220000)\end{array}$ & $\mathrm{J} / \mathrm{kg}$ \\
\hline T_H0 & 20 & $\mathbf{2 0}$ & ${ }^{\circ} \mathrm{C}$ \\
\hline T_MELT & 75 & $\begin{array}{c}75 \\
(60 \text { to } 80)\end{array}$ & ${ }^{\circ} \mathrm{C}$ \\
\hline U & 230 & $\mathbf{2 4}$ & $\mathrm{V}$ \\
\hline MAXDISPVLV & 1.5 & $\mathbf{3 . 2 5}$ & $\mathrm{mm}$ \\
\hline MAXDISPACT & 3.5 & $\mathbf{3 . 2 5}$ & $\mathrm{mm}$ \\
\hline T_CURIE & 90 & $\mathbf{9 0}$ & ${ }^{\circ} \mathrm{C}$ \\
\hline R_25 & 290 & $\begin{array}{c}50 \\
(5 \text { to } 300)\end{array}$ & $\mathrm{K} / \mathrm{W}$ \\
\hline R & 13 & $\begin{array}{c}13 \\
(0.1 \text { to } 100)\end{array}$ & $\mathrm{K} / \mathrm{W}$ \\
\hline
\end{tabular}

Table 2. Pressure difference across components in the hydraulic system with data sources, the pump head should be the sum of all other pressure drops

\begin{tabular}{|c|c|}
\hline Component & dp, $\mathbf{k P a}$ \\
\hline Pump [27] & 30 \\
\hline Circuit balancing valve on supply side & 3.6 \\
\hline Circuit [29] & 1.1 \\
\hline Regulating valve (calculated) & 2.9 \\
\hline Heat meter [26] & 4.5 \\
\hline Balancing valve [25] & 10.8 \\
\hline 10 knees [29] & 7.1 \\
\hline Three-way valve in mixing station $(\mathrm{Kv}=8)$ & 0.1 \\
\hline
\end{tabular}

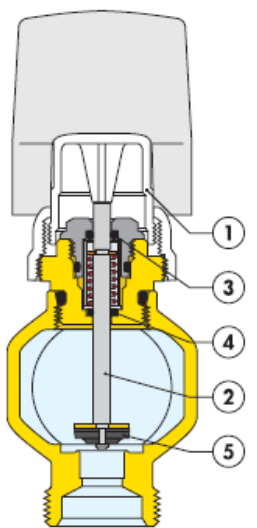

(a)

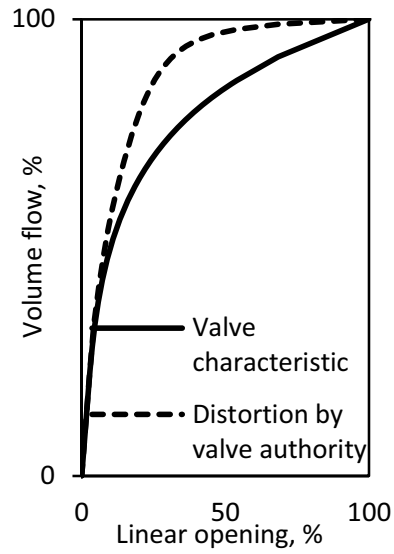

(b)
Figure 4. (a) Valve cross-section showing the valve shape (5) to indicate quick-opening valve [30] and (b) the corresponding (theoretical) valve characteristic curve, also distorted by valve authority

Table 3. Configuration of initial values and tested value ranges of input parameters for surface temperature optimization

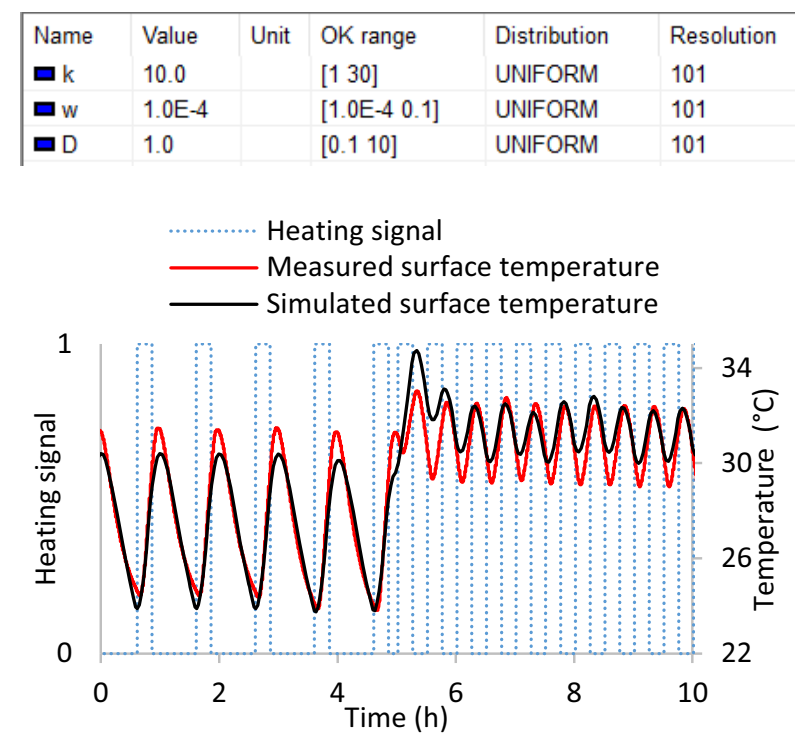

Figure 5. Actuator surface temperature fitting results

\section{Results}

\subsection{Surface temperature estimation}

The GenOpt optimization parameters for calibrating wax motor surface temperature were set up as shown in Table 3. The found optimal values were $\mathrm{k}=18.5$, $\mathrm{D}=0.56$, and $\mathrm{w}=0.0011$. The MAE (mean absolute error) for the simulated period was $0.67 \mathrm{~K}$. Comparison of fitted and measured temperatures is shown in Figure 5. 


\subsection{Actuator model}

\subsubsection{Physical model parameters}

The temperature model from the previous section was included for calibrating the physical model to Phase 1 data. The wax motor parameters were defined for the optimization of linear piston movement as shown in Table 4. The minimal stroke MAE of $0.14 \mathrm{~mm}$ was reached at melting temperature $72{ }^{\circ} \mathrm{C}$, specific heat for fluid 2910 and for solid $2930 \mathrm{~J} / \mathrm{kgK}$. Melting heat was achieved at $203 \mathrm{~J} / \mathrm{g}$. The thermal resistance to ambient was set to $52 \mathrm{~K} / \mathrm{W}, \mathrm{PTC}$ resistance at $25^{\circ} \mathrm{C}$ to $97 \mathrm{~K} / \mathrm{W}$. The wax mass value of $1 \mathrm{~g}$ was reached. The comparison with measurements will be shown in Section 3.2.3. Running the optimization with different sets of variables and fixed parameters as well as different ranges, orders, and initial values, different results can be achieved. Further analysis would be needed in the future to detect an even better combination of parameters.

Table 4. Optimization parameters for piston movement calibration

\begin{tabular}{|c|c|c|c|c|c|}
\hline Name & Value & Unit & OK range & Distribution & Resolution \\
\hline 口T_MELT & 75.0 & ${ }^{\circ} \mathrm{C}$ & {$\left[\begin{array}{ll}60 & 80\end{array}\right]$} & UNIFORM & 21 \\
\hline - CP_FLU & 2100.0 & $\mathrm{~J} /(\mathrm{kg} \mathrm{K})$ & {$\left[\begin{array}{lll}2100 & 3000\end{array}\right]$} & UNIFORM & 21 \\
\hline - CP_SOL & 2100.0 & $\mathrm{~J} /(\mathrm{kg} \mathrm{K})$ & {$\left[\begin{array}{lll}2100 & 3000\end{array}\right]$} & UNIFORM & 21 \\
\hline - L_SOLID & 210000.0 & $\mathrm{~J} / \mathrm{kg}$ & [200000 220000] & UNIFORM & 21 \\
\hline - R[1] & 13.0 & $\mathrm{~K} W \mathrm{~W}$ & {$[0.1100]$} & UNIFORM & 21 \\
\hline - $\mathrm{R} \_25$ & 50.0 & KNW & {$\left[\begin{array}{ll}5 & 300]\end{array}\right.$} & UNIFORM & 21 \\
\hline $\boldsymbol{D M}^{-}$ & $8.0 E-4$ & $\mathrm{~kg}$ & {$\left[\begin{array}{lll}5.0 E-4 & 0.002\end{array}\right]$} & UNIFORM & 21 \\
\hline
\end{tabular}

\subsubsection{Characteristic curve parameters}

The characteristic curve parameters measured for each period in the 8-hour experiment in Phase 1 are shown in Figure 6. We can see that in total, the actuator is fully opened 5.6 minutes after the heating starts and fully closed 4.4 minutes after the heating has stopped. In this test, the operation was periodic, but in the future, different patterns of heating should be applied to determine the effect of initial temperature on the characteristic curve parameters.

\subsubsection{Comparison}

We compare both the characteristic curve and the physical model in the same period of measurements. The results are shown in Figure 7. The MAE for the characteristic curve was 0.05 and for the physical model $0.07 \mathrm{~mm}$. This is less than $5 \%$ of the absolute maximum value but $10 \%$ and $8 \%$ of the average stroke, respectively, during the test. However, according to the physical model, the actuator piston started moving more than 1 minute earlier both at opening and closing than seen in measurements. Character curve performed very well as it had been fit to the same data. Both models should also be tested on new data.

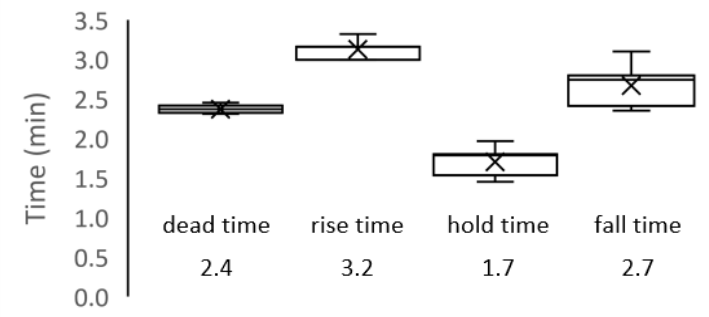

Figure 6. Characteristic curve parameters fitted to Phase 1 experimental data
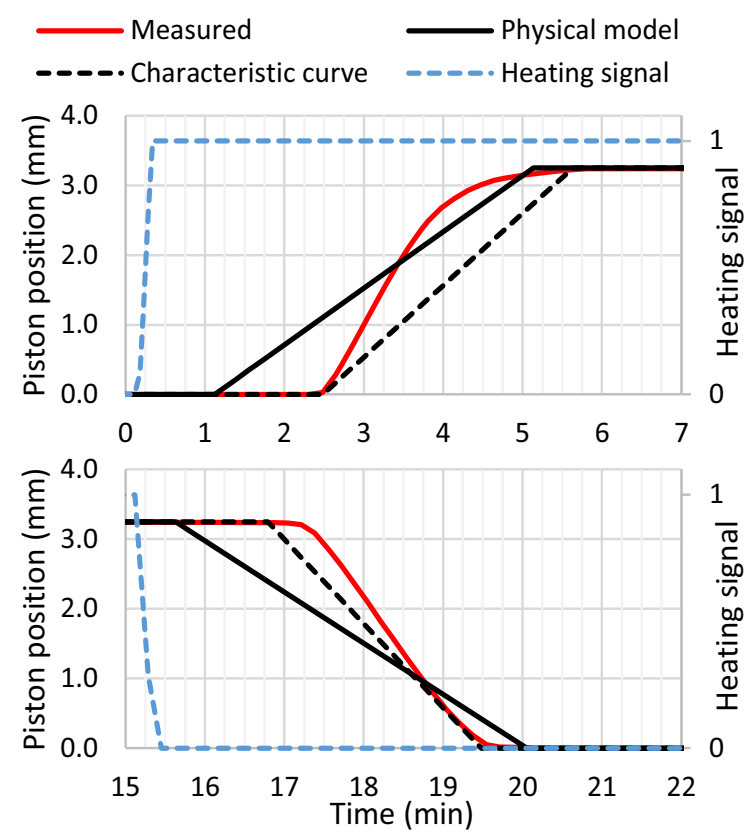

Figure 7. Stroke according to the two models compared to measurements during wax expansion (top) and contraction (bottom)
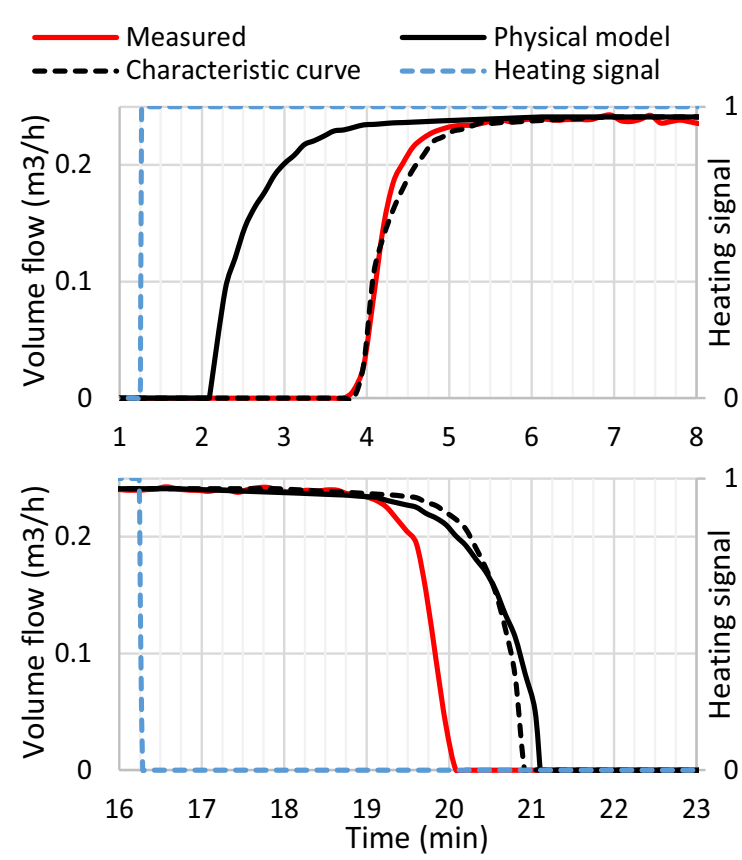

Figure 8. Volume flow according to the two models compared to measurements during wax expansion (top) and contraction (bottom) 


\subsection{Volume flow comparison}

The resulting valve characteristic and its distortion due to valve authority were the same that are shown in Figure 4 (b). Applying these to the stroke calculated from the two actuator models, we can compare the resulting volume flow dynamics. These results are shown in Figure 8. MAE of the physical model is $19 \%$ of the average volume flow during the period and the characteristic curve has MAE of $7 \%$. Characteristic curve seems to predict the increase of volume flow precisely, while with the physical model, currently almost 2 minute shift can be observed. In the cool-down, both models are a minute late.

\section{Discussion and conclusions}

The opening of the wax actuator and therefore the underfloor heating circuit from fully closed to fully open took 5.6 minutes in this study. The opening started at around 2.4 minutes (dead time). If the signal to start heating comes 5 minutes in advance from the power grid, the valves could be mostly open at the time the heating actually starts. However, it is not clear whether the 5-minute warning will be the reality and whether the opening speed of the valves is enough to ensure the heat pump would not overheat.

Both the physical and characteristic curve fit the measured data well, missing opening and closing times by maximally one minute. The translation to volume flow has larger error than modelling only the linear movement of the actuator piston. Although the mistake is small, this one or two minutes can be crucial for grid balancing. As the valve characteristic was not exactly known, the discrepancy in volume flow could be improved when the exact valve curve of the valve is known.

The main limitations of the physical model are the current implementation of heat transfer to ambient, which does not include capacity. This leads to the need of measured surface temperature of the motor, which is usually not available. Another limitation of this model is that the springs in the motor are not modelled. These could explain the delay effect as well.

In the current paper, the physical and the characteristic curve parameter estimation is preliminary. The physical model parameters were estimated by GenOpt but there was a large range of many parameters tested and there could have been many optimums. What is more, the experiments were short and did not include a large variety of different situations. In future, the characteristic curve parameters would need to be calculated for different situations and if needed, made dependent on the initial situation. In the future, the pure hysteresis model used in the actuator industry should be analysed as well.
This research was supported by the Estonian Centre of Excellence in Zero Energy and Resource Efficient Smart Buildings and Districts, ZEBE (grant 2014-2020.4.01.150016) funded by the European Regional Development Fund, by the European Commission through the H2020 project Finest Twins (grant No. 856602) and the Estonian Research Council grant (PSG409).

\section{References}

[1] IEA and UNEP, 2019 Global Status Report for Buildings and Construction, vol. 224. 2019.

[2] G. Reynders, T. Nuytten, and D. Saelens, "Potential of structural thermal mass for demand-side management in dwellings," Build. Environ., vol. 64, pp. 187-199, Jun. 2013.

[3] S. Ø. Jensen et al., "IEA EBC Annex 67 Energy Flexible Buildings," Energy Build., vol. 155, pp. 25-34, Nov. 2017.

[4] H. Wolisz, T. M. Kull, D. Müller, and J. Kurnitski, "Self-learning model predictive control for dynamic activation of structural thermal mass in residential buildings," Energy Build., vol. 207, p. 109542, 2020.

[5] L. Zhang, N. Good, and P. Mancarella, "Building-to-grid flexibility: Modelling and assessment metrics for residential demand response from heat pump aggregations," Appl. Energy, vol. 233-234, pp. 709-723, Jan. 2019.

[6] M. Lindahl, "Grid Flexible Control of Heat Pumps," HPT - Heat Pumping Technologies, 2020.

[7] S. Tibbitts, "High output paraffin actuators: utilization in aerospace mechanisms," 1988.

[8] "Thermal Actuators - Wax Motors Thermostatic wax powered linear actuators." [Online]. Available:

https://www.vernatherm.com/thermal_actuator s.html. [Accessed: 11-Mar-2021].

[9] M. Wetter, "A Modelica-based Model Library for Building Energy and Control Systems," 2009.

[10] A. Mann, T. Germann, M. Ruiter, and P. Groche, "The challenge of upscaling paraffin wax actuators," Mater. Des., vol. 190, p. 108580, May 2020.

[11] F. Goia, G. Chaudhary, and S. Fantucci, "Modelling and experimental validation of an algorithm for simulation of hysteresis effects in phase change materials for building components," Energy Build., vol. 174, pp. 5467, Sep. 2018.

[12] J. I. Lipton, S. Angle, and H. Lipson, "3D Printable Wax-Silicone Actuators."

[13] J. I. Lipton, S. Angle, R. E. Banai, E. Peretz, and H. Lipson, "Electrically Actuated Hydraulic Solids ," Adv. Eng. Mater., vol. 18, no. 10, pp. 1710-1715, Oct. 2016.

[14] A. Mann, C. Bürgel, and P. Groche, “A 
Modeling Strategy for Predicting the Properties of Paraffin Wax Actuators," Actuators, vol. 7, no. 4, p. 81, Nov. 2018.

[15] "IDA Indoor Climate and Energy 4.8." Equa Simulations AB, 2018.

[16] "Electric Thermal Actuator - TRV head|Balancing valve|Thermal Actuator|Manifolds|PICV." [Online]. Available: https://www.muyytec.com/portfolioitems/electric-thermal-actuator/. [Accessed: 11Mar-2021].

[17] T. Kalema, G. Johannesson, P. Pylsy, and P. Hagengran, "Accuracy of Energy Analysis of Buildings: A Comparison of a Monthly Energy Balance Method and Simulation Methods in Calculating the Energy Consumption and the Effect of Thermal Mass," J. Build. Phys., vol. 32, no. 2, pp. 101-130, Oct. 2008.

[18] Polytherm Heating Systems, "OEM-Actuator 24V."

[19] M. Wetter, "GenOpt ${ }^{\circledR}$-- A Generic Optimization Program," in Seventh International IBPSA Conference, 2001.

[20] Danfoss, “Actuator ABNM A5 0-10 V Proportional For Use with RA2000 Valves."

[21] N. Ukrainczyk, S. Kurajica, and J. Šipušić, "Thermophysical comparison of five commercial paraffin waxes as latent heat storage materials," Chem. Biochem. Eng. Q., vol. 24, no. 2, pp. 129-137, 2010.

[22] M. Freund, R. Csikós, S. Keszthelyi, and G. Y. Mózes, Paraffin Products Properties,

Technologies, Applications, vol. Volume 14. 1982.

[23] "Thermometrics Product Line PTC Thermistors Positive Temperature Coefficient Thermistors," 2015.

[24] R. Components, "Thermistors," 1997. [Online]. Available: https://www.thierrylequeu.fr/data/NTC-RS.pdf. [Accessed: 11Mar-2021].

[25] Comap, “750 Static balancing valve,” 2014.

[26] Sensus, "Ultrasonic Meter for heating and cooling energy nominal sizes q p 0.6 to $60 \mathrm{~m} 3$ /h PolluStat E," 2016.

[27] Grundfos, “ALPHA2 Installation and operating instructions," 2012.

[28] J. C. Inc., "Valve and Actuator Manual, Section Vb1: Valves," 1994.

[29] T. Kalamees et al., "Korterelamute välispiirete lisasoojustamise sõlmejoonised ja tüüpkorterite ventilatsioonilahendused," 2015.

[30] "Pre-assembled distribution manifolds for radiant panel systems series $663 \& 668$ S 1 Function." 